\title{
Video Article \\ Imaging Pheromone Sensing in a Mouse Vomeronasal Acute Tissue Slice Preparation
}

\author{
Julien Brechbühl ${ }^{1}$, Gaëlle Luyet ${ }^{1}$, Fabian Moine ${ }^{1}$, Ivan Rodriguez ${ }^{2}$, Marie-Christine Broillet ${ }^{1}$ \\ ${ }^{1}$ Department of Pharmacology and Toxicology, University of Lausanne \\ ${ }^{2}$ Department of Genetics and Evolution, University of Geneva
}

Correspondence to: Marie-Christine Broillet at Marie-Christine.Broillet@unil.ch

URL: https://www.jove.com/video/3311

DOI: doi:10.3791/3311

Keywords: Neuroscience, Issue 58, Vomeronasal organ, VNO, pheromone, calcium imaging, tissue slice preparation, floating immunohistochemistry, GFP

Date Published: 12/6/2011

Citation: Brechbühl, J., Luyet, G., Moine, F., Rodriguez, I., Broillet, M.C. Imaging Pheromone Sensing in a Mouse Vomeronasal Acute Tissue Slice Preparation. J. Vis. Exp. (58), e3311, doi:10.3791/3311 (2011).

\section{Abstract}

Peter Karlson and Martin Lüscher used the term pheromone for the first time in $1959^{1}$ to describe chemicals used for intra-species communication. Pheromones are volatile or non-volatile short-lived molecules ${ }^{2}$ secreted and/or contained in biological fluids $s^{3,4}$, such as urine, a liquid known to be a main source of pheromones ${ }^{3}$. Pheromonal communication is implicated in a variety of key animal modalities such as kin interactions $s^{5,6}$, hierarchical organisations ${ }^{3}$ and sexual interactions ${ }^{7,8}$ and are consequently directly correlated with the survival of a given species $^{9,10,11}$. In mice, the ability to detect pheromones is principally mediated by the vomeronasal organ (VNO) $)^{10,12}$, a paired structure located at the base of the nasal cavity, and enclosed in a cartilaginous capsule. Each VNO has a tubular shape with a lumen ${ }^{13,14}$ allowing the contact with the external chemical world. The sensory neuroepithelium is principally composed of vomeronasal bipolar sensory neurons (VSNs) ${ }^{15}$. Each VSN extends a single dendrite to the lumen ending in a large dendritic knob bearing up to 100 microvilli implicated in chemical detection ${ }^{16}$. Numerous subpopulations of VSNs are present. They are differentiated by the chemoreceptor they express and thus possibly by the ligand(s) they recognize ${ }^{17,18}$. Two main vomeronasal receptor families, V1Rs and V2Rs ${ }^{19,20,21,22}$, are composed respectively by $240^{23}$ and $120^{24}$ members and are expressed in separate layers of the neuroepithelium. Olfactory receptors (ORs) ${ }^{25}$ and formyl peptide receptors (FPRs) ${ }^{26,27}$ are also expressed in VSNs.

Whether or not these neuronal subpopulations use the same downstream signalling pathway for sensing pheromones is unknown. Despite a major role played by a calcium-permeable channel (TRPC2) present in the microvilli of mature neurons ${ }^{28}$ TRPC2 independent transduction channels have been suggested ${ }^{6,29}$. Due to the high number of neuronal subpopulations and the peculiar morphology of the organ, pharmacological and physiological investigations of the signalling elements present in the VNO are complex.

Here, we present an acute tissue slice preparation of the mouse VNO for performing calcium imaging investigations. This physiological approach allows observations, in the natural environment of a living tissue, of general or individual subpopulations of VSNs previously loaded with Fura-2AM, a calcium dye. This method is also convenient for studying any GFP-tagged pheromone receptor and is adaptable for the use of other fluorescent calcium probes. As an example, we use here a VG mouse line ${ }^{30}$, in which the translation of the pheromone V1rb2 receptor is linked to the expression of GFP by a polycistronic strategy.

\section{Video Link}

The video component of this article can be found at https://www.jove.com/video/3311/

\section{Protocol}

\section{Dissection of the mouse VNO}

1. Use adult mice. As pheromone sensing is implicated in multimodalities, careful distinction between strains, genotypes, sexes and ages is important and will influence your results. Here, we choose adult VG mice ${ }^{30}$ previously used for the identification of a pheromone-receptor pair (2-heptanone-V1rb2) ${ }^{31}$ (Fig. 1A).

2. Before starting the dissection, prepare fresh cold artificial cerebro-spinal fluid (ACSF; $\mathrm{NaCl} 118 \mathrm{mM}, \mathrm{NaHCO} 325 \mathrm{mM}, \mathrm{D}-\mathrm{Glucose} 10 \mathrm{mM}$, $\mathrm{KCl} 2 \mathrm{mM}, \mathrm{MgCl}_{2} 2 \mathrm{mM}, \mathrm{NaH}_{2} \mathrm{PO}_{4} 1.2 \mathrm{mM}, \mathrm{CaCl}_{2} 2 \mathrm{mM}$; pH 7.4) saturated with oxycarbon $\left(95 \% \mathrm{O}_{2}: 5 \% \mathrm{CO}_{2}\right)$. For that, mix all the ACSF components except $\mathrm{CaCl}_{2}$. Saturate the solution by directly bubbling it with oxycarbon. In the end, add the $\mathrm{CaCl}_{2}$ and adjust with ddd $\mathrm{H}_{2} \mathrm{O}$ to the desired volume. Keep the ACSF solution on ice until use.

3. Euthanasia of the mouse should be preferentially done by cervical dislocation or by $\mathrm{CO}_{2}$ inhalation just before the experiment.

4. Cut the mouse head. Place it under a dissecting microscope in cold ACSF continuously oxycarbonated.

5. Cut the lower jaw and position the head in order to visualize the palate (Fig. 1B). 
6. Make an incision horizontally in the upper part of the palate (Fig. 1B) with micro scissors and remove the palate membrane with micro dissecting forceps. Hydrate and clean the exposed cavity with ACSF (Fig. 1C).

7. Cut the upper and the lower part of the nasal septum (Fig. 1C). Delicately extract the nasal septum containing the VNO and place it directly in ACSF on ice (Fig. 1D).

8. Separate vertically the two parts of the VNO using micro dissecting forceps and delicately remove the cartilaginous capsule of the VNO (Fig. 1E). Make sure that all the cartilaginous pieces are removed.

\section{VNO tissue slice preparation}

The VNO tissue slice preparation described in this section 2) is mainly for calcium imaging investigations. VNO slices can also be used for immunohistostainings on floating slices to verify the structural integrity of the tissue (please see section 3 ) of the protocol).

1. Prepare low-melting agar (3\% in standard PBS) and your working place. You will need ACSF, a microtome and supports, micro dissecting forceps, embedding molds $(22 \times 22 \times 20 \mathrm{~mm})$, precision wipes, brushes, tissue culture plates, cyanacrylat glue, ice and a thermometer.

2. Fill the embedding mold with $3 \%$ low-melting agar. Make sure that the temperature is not higher than $41^{\circ} \mathrm{C}$ before placing vertically the shortly wiped VNO (Fig. 2A) to be able to obtain coronal slices.

3. Place the embedding mold on ice for 1 min until solidification and then separate it from the agar block. Cut the agar block in a pyramida shape and place it with glue on the microtome support (Fig. 2B).

4. Cut coronal VNO slices with the microtome, with a speed of $0.5 \mathrm{~mm} / \mathrm{s}$, an amplitude of $0.7 \mathrm{~mm}$ and a thickness of $100 \mu \mathrm{m}$ in cold ACSF and collect the tissue slices with a brush before placing them in a tissue culture plate filled with cold ACSF.

5. If your slices contain endogenous fluorescence like GFP (in gene-targeted neurons) you can select them under a fluorescent stereomicroscope (Fig. 2C).

\section{Immunohistochemistry on VNO floating slices}

The goal of this procedure is to verify the integrity of the VNO tissue slices obtained in section 2). Acetylated-tubulin is a microtubule / cytoskeleton marker expressed in dendrites and microvilli of VNO sensory neurons. For calcium imaging experiments, go directly to section 4 of the protocol. The immunohistostaining method on floating VNO slices can be adapted to the evaluation of the expression of any protein of interest. For this purpose, we recommend that you fix the VNO for $1 \mathrm{~h}$ at $4{ }^{\circ} \mathrm{C}$ in a fixative solution (paraformaldehyde $4 \%$ in $\mathrm{PBS}$, $\mathrm{pH} 7.6$ ) after the point 1.7) of the protocol and use from this point PBS at $\mathrm{pH} 7.6$ rather than ACSF solution.

1. In the tissue culture plate, fix your slices of interest in a fixative solution (paraformaldehyde $4 \%$ in $\mathrm{PBS}, \mathrm{pH} 7.6$ ) $1 \mathrm{~h}$ at $4^{\circ} \mathrm{C}$.

2. Block your tissue slices overnight at $4^{\circ} \mathrm{C}$ in a PBS solution containing NGS (normal goat serum) $10 \%$ and triton X-100 at $0.5 \%$.

3. Incubate slices with the primary antibody (anti-acetylated-tubulin, Mouse, 1:2000) for $16 \mathrm{~h}$ at room temperature (RT) in a PBS solution containing NGS $5 \%$ and Triton X-100 at $0.25 \%$.

4. Wash 3 times for 5 minutes with a PBS solution containing NGS $2 \%$.

5. Incubate in the dark with the secondary antibody (Cy5-conjugated Goat anti-Mouse, 1:200) in a PBS solution containing NGS $2 \%$ for 1 h at RT.

6. Wash 3 times for 5 minutes with PBS containing NGS $2 \%$, PBS NGS $1 \%$ and PBS only.

7. Mount your slices in a fluorescent mounting media (containing or not DAPI) by placing them in the centre of the hydrophobic delimited zones (use a hydrophobic pen) and cover the slices with coverslips.

8. Make observations and acquisitions with confocal microscopy and a software allowing 3D reconstructions (Fig. 2D-F).

\section{Calcium imaging on VNO slices}

1. The following procedures will take place in the dark. Incubate VNO slices for $1 \mathrm{~h}$ at $37^{\circ} \mathrm{C}$ in a loading solution composed of cold ACSF with Fura-2AM ( $7 \mu \mathrm{M}$; stock solution of $1 \mathrm{mM}$ in DMSO) and pluronic $0.1 \%\left(\mathrm{w} / \mathrm{v}\right.$; stock solution at $20 \%$ in $\left.\mathrm{ddH}_{2} \mathrm{O}\right)$.

2. Keep the loaded slices on ice with oxycarbonation until use. Loaded slices can be kept for 3-4h.

3. Place the loaded slices with a brush in a perfusion chamber containing ACSF and maintain the slices with a tissue slice anchor (Fig. 3A).

4. Place the perfusion chamber on the stage of a calcium imaging microscope (Fig. 3B) and continuously perfuse with oxycarbonated ACSF at RT. Temperature can be adapted with the use of a bipolar temperature controller.

5. Observations of the loaded VNO slices (Fig. 3C-E) are performed with an inverted fluorescence microscope, with a $25 x$ or $63 x$ objective and a CooL SNAP-HQ camera. Illumination is done sequentially $(340 / 380 \mathrm{~nm})$ with a polychromator instrument and recorded at a rate of $5 \mathrm{~Hz}$. Filtered emission is done at $510 \mathrm{~nm}$. Intracellular calcium ratio changes $(\Delta \mathrm{F}=340 \mathrm{~nm} / 380 \mathrm{~nm})$ are monitored with an appropriate software.

6. Chemostimulation should be selected according to your own experimental purpose. Here, perfusions of ACSF containing a pheromone mix (isobutylamine, 2-heptanone, 4-heptanone, 2-heptanol, pentylacetate, dimethylpyrazine, $\alpha / \beta$-farnesene, $\left.10^{-6} \mathrm{M}\right)$, 2-heptanone $\left(10^{-6} \mathrm{M}\right)$ or freshly collected male and female $(1: 1)$ mouse urine $(1: 100)$ are performed ${ }^{32}$. Perfusion of ATP $(125 \mu \mathrm{M})$ is used as a viability test at the end of the experiments (Fig. 3F) and should indicate a proportion of approximately $80 \%$ viable neurons. Under these conditions, slices can be used up to 2 hours.

7. GFP-tagged subpopulations of sensory neurons are visualised by specific illumination (here the V1rb2 expressing neurons) and can be analysed precisely (Fig. 3G-I).

\section{Representative Results:}

To establish a functional assay to investigate the multi transduction pathways taking place in the mouse VNO, or to identify new pheromonereceptor pairs, we take advantage of the VG mouse line (Fig. 1A). In this line, one out of 240 V1Rs receptors, the V1Rb2 receptor is GFP-tagged allowing the easy visualization of a particular subpopulation of vomeronasal sensory neurons. After extraction and dissection of the VNO (Fig. 1E), we prepare acute VNO slices (Fig. 2C). We fix a fraction of them, in order to check and validate the tissular integrity of the preparation by 
performing immunohistostainings against the acetylated-tubulin protein (Fig. 2D-F). The other fraction of the slices is used for calcium imaging experiments. For that, slices are loaded with Fura-2AM (Fig. 3C-E) and the intracellular calcium level of each neuron is monitored as a $\Delta F$ ratio (Fig. 3F). Viability of the neurons is evaluated by perfusion of ATP $(125 \mu \mathrm{M})$, after which rapid and transient increase of the $\Delta \mathrm{F}$ ratio is expected (Fig. 3F). Urine being a major source of pheromones, perfusion of freshly collected mouse urine (1:100) is used as an endogenous control. It triggers calcium transients in approximately $50 \%$ of the recorded neurons (cell 1 and 2, Fig. 3F). Under GFP illumination, V1Rb2 positive neurons are observable, and perfusion of its known pheromonal ligand, 2-heptanone, initiates cellular activation (cell 1, Fig. 3I). Interestingly, neuronal activations are also observable in a fraction of neurons that do not express the V1Rb2 receptor (GFP negative neurons) (cell 2, Fig. 3I), demonstrating the complexity of pheromone coding in the VNO.
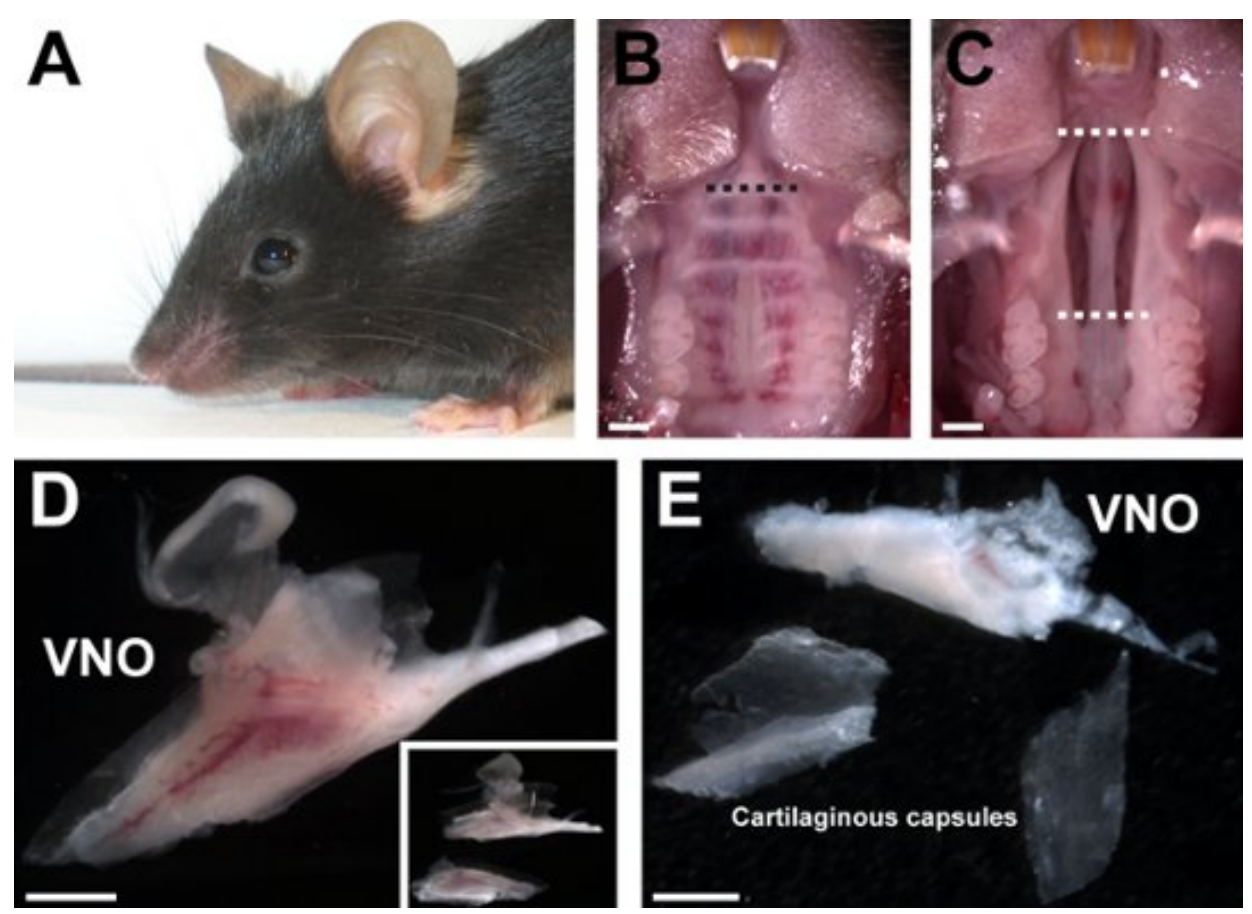

Figure 1. Dissection of the mouse vomeronasal organ. (A) A mouse from the VG line. (B) After euthanasia of the mouse, the full head is placed under a binocular microscope and the lower jaw is removed in order to visualize the palate. A small horizontal incision is done (black dashed line). (C) After the removal of the palate, the nasal septum lined with the VNO is cut in the upper and the lower part (white dashed lines) to facilitate VNO extraction. (D) The VNO is positioned in ACSF solution and separated (insert : higher power view of the two parts). (E) The cartilaginous capsule of the VNO is delicately removed, and the VNO without its cartilaginous capsule is used for the rest of the experiments. Scale bars are: B-E, $1 \mathrm{~mm}$. 

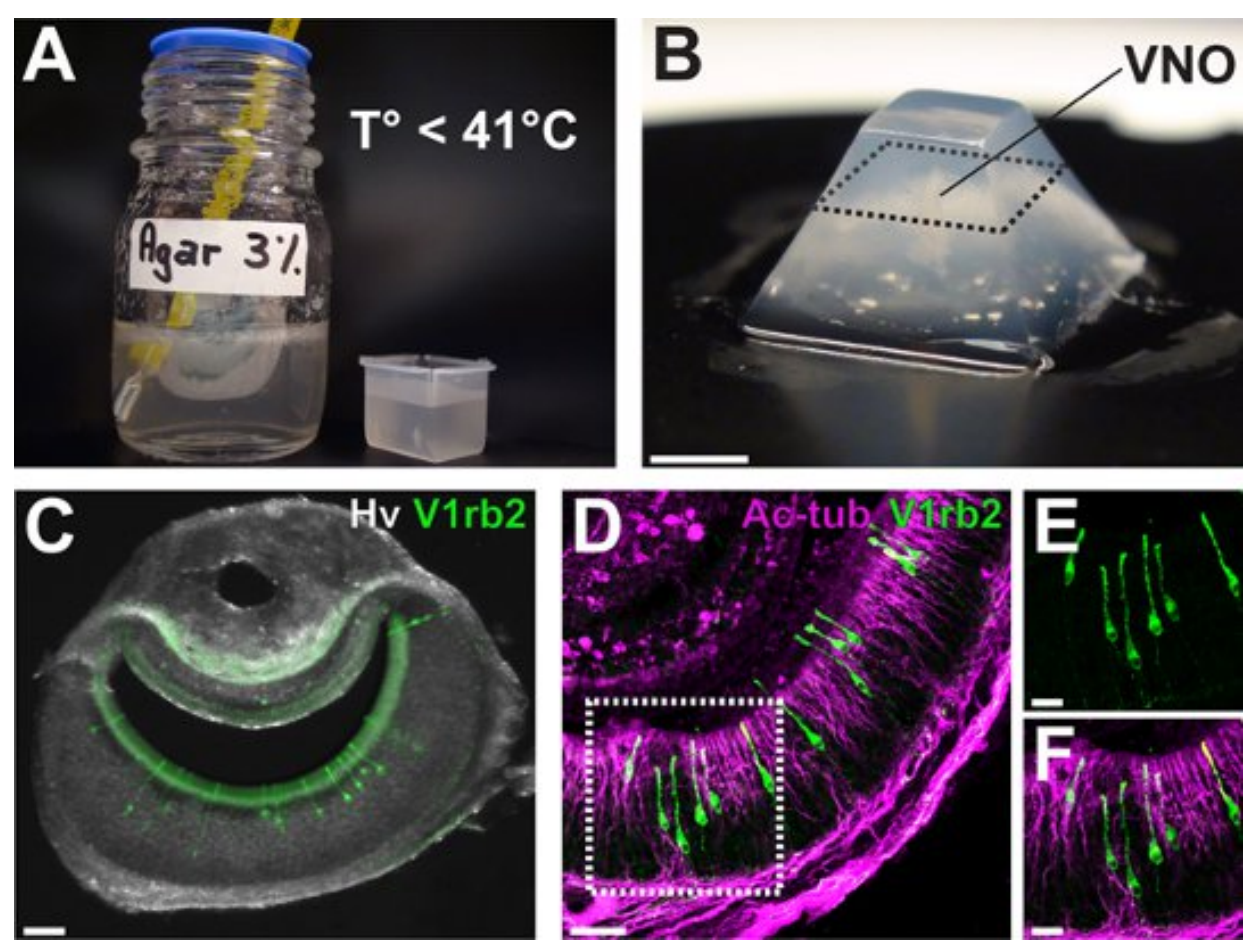

Figure 2. Mouse vomeronasal acute slice preparation and tissular integrity. (A) The mouse VNO is vertically embedded in an agar $3 \%$ solution. The temperature of the agar must be lower than $41^{\circ} \mathrm{C}$. (B) The agar block is cut in a pyramidal shape and $100 \mu \mathrm{m}$ VNO sections (black dashed line) are generated in ACSF. (C) VNO slices can be selected under a fluorescent stereomicroscope in order to visualize a specific population of tagged sensory neurons. (D-F) Tissular integrity can be evaluated by immunohistostainings against the acetylated-tubulin protein, a higher power view of the V1rb2 gene-targeted neurons demonstrate the perfect conservation of the preparation. Neurons with their long dendrites reaching the surface of the lumen $(E)$ as well as the expression of the structural protein in the dendritic knobs and microvilli can be observed $(F)$. Scale bars are: $\mathrm{B}, 5 \mathrm{~mm} ; \mathrm{C}, 60 \mu \mathrm{m} ; \mathrm{D}, 40 \mu \mathrm{m} ; \mathrm{E}-\mathrm{F}, 20 \mu \mathrm{m}$. 

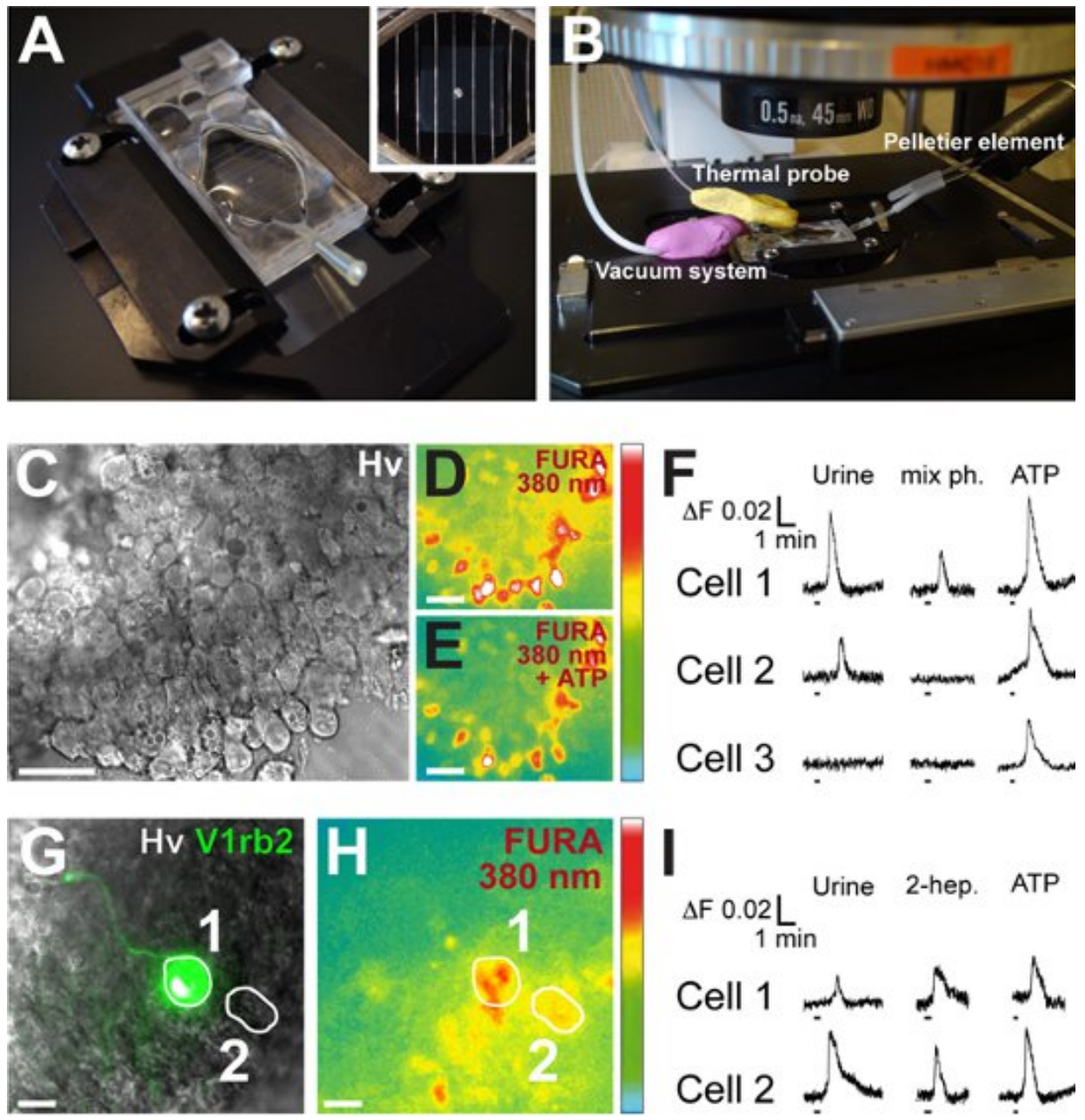

Figure 3. Calcium imaging and pheromone detection in vomeronasal acute tissue slices. (A) After a Fura-2AM loading phase, VNO slices are placed in a perfusion chamber and are maintained with an adapted anchor (high power view). (B) Experiments are performed in the dark and VNO slices are continuously perfused with ACSF at RT with a vacuum system. The temperature can be chosen using a temperature controller system composed by a bipolar Pelletier element and a thermal probe. This particular experiment was performed at RT. (C-E) VNO slices are observable under Hoffman phase contrast (C, Hv) or Fura $380 \mathrm{~nm}$ illumination before (D) and during neuronal activation (E, here with ATP). (F) Neuronal viability is evaluated with perfusion of ATP $(125 \mu \mathrm{M})$. Here, chemostimulation is done with urine (Urine, 1:100) or with a mix of mouse pheromones (mix ph., $10^{-6} \mathrm{M}$ ) at a constant flow rate of $165 \mathrm{ml} / \mathrm{h}$. Intracellular calcium levels $(\Delta \mathrm{F})$ can be recorded individually for each cell (Cell 1 to 3). (G) A V1Rb2 neuron is visualized under GFP illumination (1). (H) The loading of this neuron (1) as well as a non-V1rb2 expressing neuron (2) is shown. (I) The V1rb2 neuron is able to respond to 2-heptanone with an intracellular calcium increase. This particular non-V1rb2 expressing neuron also responds to 2-heptanone (cell 2). Scale bars are: C-E, $20 \mu \mathrm{m} ; \mathrm{G}-\mathrm{H}, 15 \mu \mathrm{m} ; \Delta \mathrm{F}=340 \mathrm{~nm} / 380 \mathrm{~nm}$. (F and I) Duration of stimulus application is indicated by bars under each trace. The arbitrary color scale represents the fluorescence intensity.

\section{Discussion}

The calcium imaging method presented here enables to record, in an acute slice preparation, the pheromonal responses of mouse VNO neurons. With this approach, dissection from the animal to the vomeronasal neurons is, with some practice, easily achievable and provides a long-living tissue preparation. It allows time-consuming experiments like pharmacological investigations or the study of pheromonal coding. With this physiological technique, large populations as well as precise neuronal subpopulations can be analysed specifically. In addition, this method can be easily adapted to immunohistochemical approaches or experiments based on other calcium dyes. The use of these combined methodologies will surely allow the identification of new pheromonal ligands for the many orphan chemoreceptors expressed in the mouse vomeronasal organ.

\section{Disclosures}

No conflicts of interest declared. 


\section{Acknowledgements}

We want to thank particularly Monique Nenniger Tosato for her excellent technical support as well as Jean-Yves Chatton for his scientific advices and the imaging CIF platform of the UNIL for the microscope equipment. Funding was provided by the Swiss National Science Foundation.

\section{References}

1. Karlson, P. \& Lüscher, M. "Pheromones" a new term for a class of biologically active substances. Nature. 183, 55-56 (1959).

2. Cavaggioni, A., Mucignat-Caretta, C., Redaelli, M., \& Zagotto, G. The scent of urine spots of male mice, Mus musculus: Changes in chemical composition over time. Rapid Commun. Mass Spectrom. 20, 3741-3746, doi:10.1002/rcm.2789 (2006).

3. Novotny, M., Harvey, S., \& Jemiolo, B. Chemistry of male dominance in the house mouse, Mus domesticus. Experientia. 46, 109-113 (1990).

4. Leinders-Zufall, T., et al. Ultrasensitive pheromone detection by mammalian vomeronasal neurons. Nature. 405, 792-796 (2000).

5. Leinders-Zufall, T., et al. MHC class I peptides as chemosensory signals in the vomeronasal organ. Science. 306, 1033-1037 (2004).

6. Leinders-Zufall, T., Ishii, T., Mombaerts, P., Zufall, F., \& Boehm, T. Structural requirements for the activation of vomeronasal sensory neurons by MHC peptides. Nat. Neurosci. 12, 1551-1558 (2009).

7. Jemiolo, B., Xie, T.M., \& Novotny, M. Socio-sexual olfactory preference in female mice: attractiveness of synthetic chemosignals. Physiol. Behav. 50, 1119-1122 (1991).

8. Achiraman, S. \& Archunan, G. Characterization of urinary volatiles in Swiss male mice (Mus musculus): bioassay of identified compounds. J. Biosci. 27, 679-686 (2002).

9. Dulac, C. \& Torello, A.T. Molecular detection of pheromone signals in mammals: from genes to behaviour. Nat. Rev. Neurosci. 4, 551-562 (2003).

10. Brennan, P.A. \& Zufall, F. Pheromonal communication in vertebrates. Nature. 444, 308-315 (2006).

11. Mondor, E.B. \& Roitberg, B.D. Inclusive fitness benefits of scent-marking predators. Proc. Biol. Sci. 271 Suppl 5, S341-343 (2004).

12. Holy, T.E., Dulac, C., \& Meister, M. Responses of vomeronasal neurons to natural stimuli. Science. 289, 1569-1572 (2000).

13. Keverne, E.B. The Vomeronasal Organ. Science. 286, 716-720 (1999).

14. Weiler, E. Postnatal development of the rat vomeronasal organ. Chem. Senses. 30 Suppl 1, i127-i128 (2005).

15. Zufall, F., Kelliher, K.R., \& Leinders-Zufall, T. Pheromone detection by mammalian vomeronasal neurons. Microsc. Res. Tech. 58, 251-260 (2002).

16. Ciges, M., Labella, T., Gayoso, M., \& Sanchez, G. Ultrastructure of the organ of Jacobson and comparative study with olfactory mucosa. Acta. Otolaryngol. 83, 47-58 (1977).

17. Munger, S.D., Leinders-Zufall, T., \& Zufall, F. Subsystem organization of the mammalian sense of smell. Annu. Rev. Physiol. 71, 115-140 (2009).

18. Mombaerts, P. Genes and ligands for odorant, vomeronasal and taste receptors. Nat. Rev. Neurosci. 5, $263-278$ (2004).

19. Ryba, N.J.P. \& Tirindelli, R. A new multigene family of putative pheromone receptors. Cell. 19, 371-379 (1997).

20. Matsunami, H. \& Buck, L.B. A multigene family encoding a diverse array of putative pheromone receptors in mammals. Cell. $90,775-784$ (1997).

21. Herrada, G. \& Dulac, C. A novel family of putative pheromone receptors in mammals with a topographycally organized and sexually dimorphic distribution. Cell. 90, 763-773 (1997).

22. Dulac, C. \& Axel, R. A novel family of genes encoding putative pheromone receptors in mammals. Cell. 83, 195-206 (1995).

23. Young, J.M., Massa, H.F., Hsu, L., \& Trask, B.J. Extreme variability among mammalian V1R gene families. Genome. Res. 20, 10-18 (2009).

24. Yang, H., Shi, P., Zhang, Y.P., \& Zhang, J. Composition and evolution of the V2r vomeronasal receptor gene repertoire in mice and rats. Genomics. 86, 306-315 (2005).

25. Levai, O., Feistel, T., Breer, H., \& Strotmann, J. Cells in the vomeronasal organ express odorant receptors but project to the accessory olfactory bulb. J. Comp. Neurol. 498, 476-490 (2006).

26. Riviere, S., Challet, L., Fluegge, D., Spehr, M., \& Rodriguez, I. Formyl peptide receptor-like proteins are a novel family of vomeronasal chemosensors. Nature. 459, 574-577 (2009).

27. Liberles, S.D., et al. Formyl peptide receptors are candidate chemosensory receptors in the vomeronasal organ. Proc. Natl. Acad. Sci. U.S.A. 106, 9842-9847 (2009)

28. Liman, E.R., Corey, D.P., \& Dulac, C. TRP2: A candidate transduction channel for mammalian pheromone sensory signaling. Proc. Natl. Acad. Sci. U.S.A. 96, 5791-5796 (1999).

29. Kelliher, K.R., Spehr, M., Li, X.H., Zufall, F., \& Leinders-Zufall, T. Pheromonal recognition memory induced by TRPC2-independent vomeronasal sensing. Eur. J. Neurosci. 23, 3385-3390 (2006).

30. Rodriguez, I., Feinstein, P., \& Mombaerts, P. Variable patterns of axonal projections of sensory neurons in the mouse vomeronasal system. Cell. 97, 199-208 (1999).

31. Boschat, C., et al. Pheromone detection mediated by a V1r vomeronasal receptor. Nature. Neuroscience. 5, 1261-1262 (2002).

32. Brechbühl, J., Klaey, M., \& Broillet, M.C. Grueneberg ganglion cells mediate alarm pheromone detection in mice. Science. 321, 1092-1095 (2008). 